\title{
Evolving Role of Endoscopic Retrograde Cholangiopancreatography in Management of Extrahepatic Hepatic Ductal Injuries due to Blunt Trauma: Diagnostic and Treatment Algorithms
}

\author{
Nikhil P. Jaik, ${ }^{1}$ Brian A. Hoey, ${ }^{2,3}$ and S. Peter Stawicki ${ }^{4}$ \\ ${ }^{1}$ Department of Surgery, St Luke's Hospital and Health Network, Bethlehem, PA 18015, USA \\ ${ }^{2}$ Regional Level I Resource Trauma Center, St Luke's Hospital and Health Network, Bethlehem, PA 18015, USA \\ ${ }^{3}$ University of Pennsylvania Trauma Network, Philadelphia, PA 19104, USA \\ ${ }^{4}$ STAR/OPUS12 Foundation, 304 Monroe Boulevard, King of Prussia, PA 19406, USA
}

Correspondence should be addressed to S. Peter Stawicki, stanislaw.stawicki@stawickifoundation.org

Received 8 February 2007; Revised 13 April 2007; Accepted 2 August 2007

Recommended by Sherif Hanna

\begin{abstract}
Extrahepatic hepatic ductal injuries (EHDIs) due to blunt abdominal trauma are rare. Given the rarity of these injuries and the insidious onset of symptoms, EHDI are commonly missed during the initial trauma evaluation, making their diagnosis difficult and frequently delayed. Diagnostic modalities useful in the setting of EHDI include computed tomography (CT), abdominal ultrasonography (AUS), nuclear imaging (HIDA scan), and cholangiography. Traditional options in management of EHDI include primary ductal repair with or without a T-tube, biliary-enteric anastomosis, ductal ligation, stenting, and drainage. Simple drainage and biliary decompression is often the most appropriate treatment in unstable patients. More recently, endoscopic retrograde cholangiopancreatography (ERCP) allowed for diagnosis and potential treatment of these injuries via stenting and/or papillotomy. Our review of 53 cases of EHDI reported in the English-language literature has focused on the evolving role of ERCP in diagnosis and treatment of these injuries. Diagnostic and treatment algorithms incorporating ERCP have been designed to help systematize and simplify the management of EHDI. An illustrative case is reported of blunt traumatic injury involving both the extrahepatic portion of the left hepatic duct and its confluence with the right hepatic duct. This injury was successfully diagnosed and treated using ERCP.
\end{abstract}

Copyright (C) 2008 Nikhil P. Jaik et al. This is an open access article distributed under the Creative Commons Attribution License, which permits unrestricted use, distribution, and reproduction in any medium, provided the original work is properly cited.

\section{INTRODUCTION}

Injuries to the extrahepatic biliary system in blunt abdominal trauma are uncommon [1-7]. Extrahepatic hepatic ductal injuries (EHDIs) occur even less frequently [1-8]. Because of their rarity and the frequently insidious onset of symptoms, EHDIs are commonly missed during the initial trauma evaluation, and debate continues regarding the best way to diagnose and treat them $[2,9]$. Diagnostic tools useful in EHDIs include computed tomography (CT), abdominal ultrasound (AUS), nuclear imaging (HIDA), percutaneous transhepatic cholangiography (PTC), and endoscopic retrograde cholangiopancreatography (ERCP).
Traditional management options in EHDI include primary repair with or without a T-tube, biliary-enteric anastomosis, ductal ligation, stenting, and drainage. Simple drainage and biliary decompression is often the most appropriate treatment option in unstable patients [2, 3]. More recently, ERCP has allowed trauma surgeons to diagnose and potentially treat EHDIs via stenting and/or papillotomy, even in the face of previous abdominal surgical procedures $[4,10,11]$.

A comprehensive review of 53 cases of EHDIs reported in the English-language literature was conducted, focusing on the evolving role or ERCP in diagnosis and treatment of these injuries. We also report an illustrative case of blunt traumatic 
injury involving the extrahepatic portion of the left hepatic duct (LHD) and the confluence of the LHD and the right hepatic duct (RHD). Diagnostic and treatment algorithms that incorporate ERCP are presented in order to help systematize and simplify the management of EHDIs.

\section{ILLUSTRATIVE CASE REPORT}

A 26-year old motorcycle rider was struck on his right side by a mid-sized passenger car traveling at approximately 30 miles per hour. He was hemodynamically unstable upon arrival to the hospital (systolic blood pressure $60 \mathrm{mmHg}$, heart rate $120 / \mathrm{min}$ ). Bedside abdominal sonogram showed free peritoneal fluid. The patient remained hypotensive despite aggressive fluid resuscitation and was promptly taken to the operating room. He was found to have a large stellate laceration of the liver involving medial segments of the right lobe. Liver was packed and hemostasis was obtained. Splenectomy was performed secondary to splenic laceration that extended into the hilum. A Jackson-Pratt drain was left in the left upper quadrant (LUQ). After a damage control dressing was placed, the patient was taken to interventional radiology where several branches of the right hepatic artery were embolized.

The patient's early hospital course was uneventful and his abdomen was definitively closed on postoperative day two. However, he subsequently began draining increasing amounts of bile from his abdominal drain, associated with concurrent rise in serum bilirubin. Computed tomography (CT) of the abdomen demonstrated a large fluid collection in the upper abdomen (Figure 1). A percutaneous drain was placed into this collection and drained approximately $500 \mathrm{ml}$ of bile. Due to continued drainage of several hundred milliliters of bile per day, an ERCP was obtained. This demonstrated a proximal transection of the extrahepatic portion of the LHD as well as a leak at the confluence of LHD and RHD (Figure 2(a)). Stenting across the transected LHD was attempted but the guidewire could not be passed across the injury. A sphincterotomy was performed and the common bile duct (CBD) was stented in order to decompress the biliary tree.

Over the next several days, the drainage markedly decreased and the patient was discharged to home with drains in place. A repeat ERCP four months after patient's initial injury showed filling of both the RHD and the LHD (Figure 2(b)). His liver function tests (LFTs) at the time were within normal limits. Both the stent and drain were removed, with no subsequent problems reported. He is now four years out from his original trauma, has normal LFTs, and a recent abdominal sonogram showed normal CBD size.

\section{DISCUSSION}

The first case of bile duct rupture due to blunt abdominal trauma was reported by Wainwright in 1799 [13]. Traumatic extrahepatic biliary tree injuries are rare and usually associated with penetrating mechanism [1]. The frequencies of injuries to the biliary tree, in decreasing order, are those of gallbladder, common bile duct (CBD), hepatic ducts (HD) and junction of left hepatic duct (LHD), and right hepatic

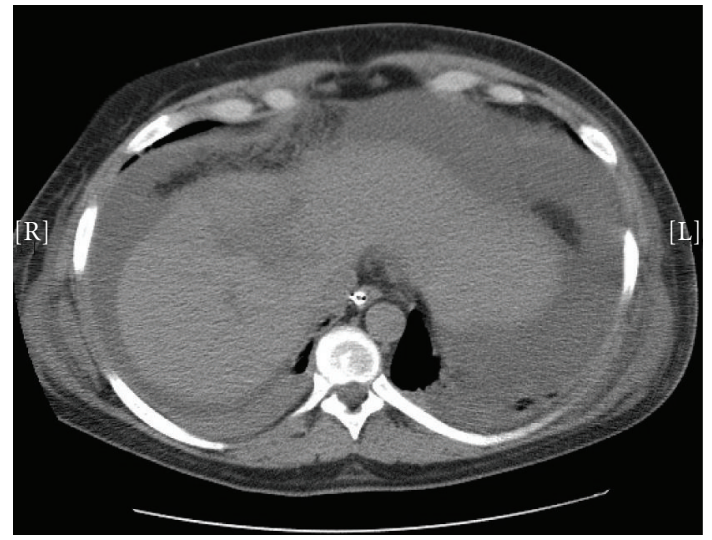

FIGURE 1: Computed tomographic (CT) scan showing a high-grade liver injury along with large amount of intraperitoneal fluid in the upper abdomen.

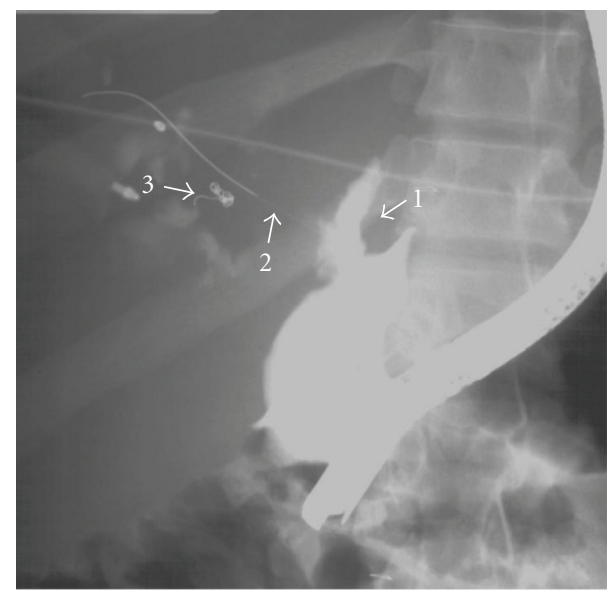

(a)

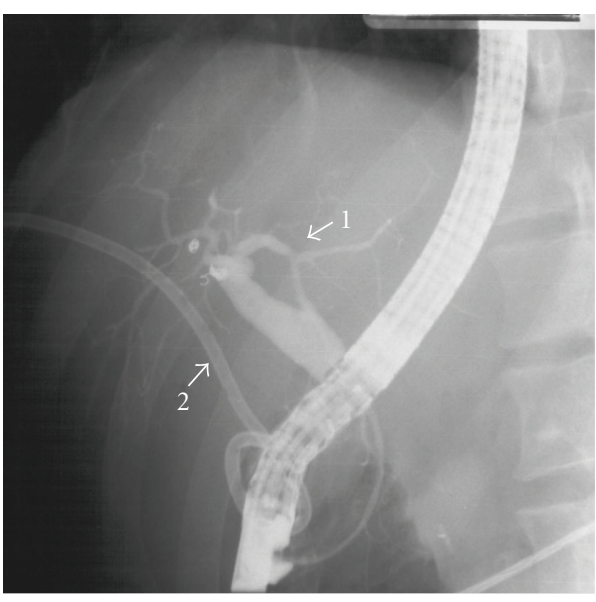

(b)

FIGURE 2: (a) Initial ERCP study demonstrating (1) left hepatic duct transection; (2) wire across the patent right hepatic duct; and (3) embolization coils. (b) Repeat ERCP study demonstrating (1) intact left hepatic duct; and (2) percutaneous drain. 


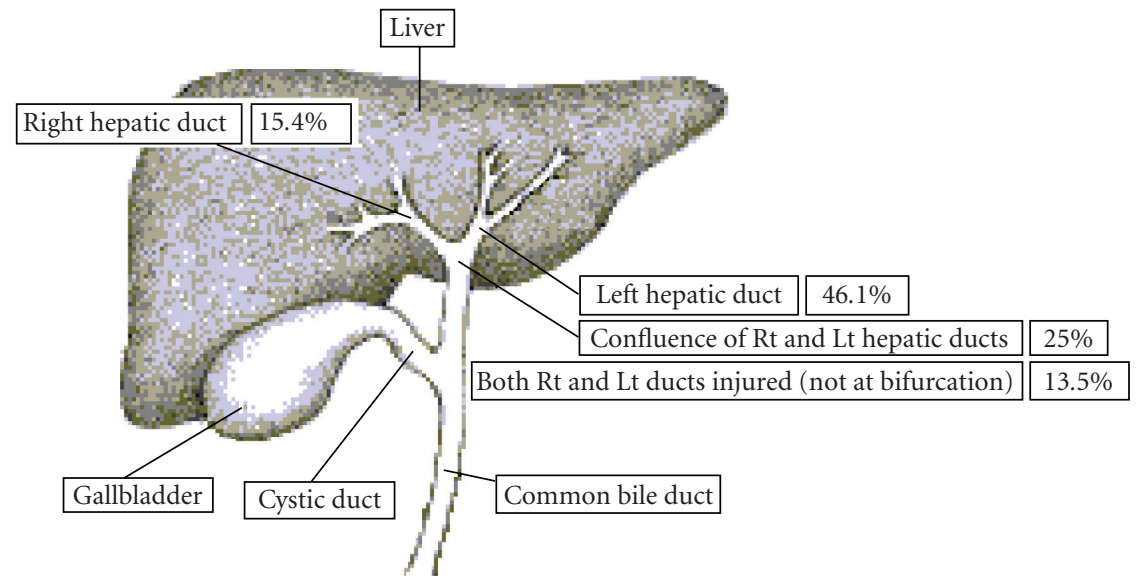

FIGURE 3: Diagram demonstrating the locations and frequencies of extrahepatic hepatic ductal injuries. Source: [12].

duct (RHD) [1, 14]. Only $2 \%$ of patients with extrahepatic biliary injury have HD injury [1]. We will first discuss the demographics, anatomy, and pathophysiology of EHDIs, followed by a description of some traditional treatment methods and a detailed discussion of the emerging role of ERCP in the treatment of EHDIs, along with diagnostic and treatment algorithms that incorporate ERCP.

Extrahepatic hepatic ductal injuries (EHDIs) occur predominantly in men, and the male-to-female ratio increases with patient age $[2,12,15]$. Approximately $50 \%$ of EHDIs are automobile-related, with the remaining half due to crush injuries, motorcycle crashes, sports/recreational injuries, and falls [12]. The rarity of EHDIs combined with over 50\% frequency of severe associated injuries contributes to an average diagnostic delay of about 2 weeks $[12,16]$. The frequencies of EHDIs locations are shown in Figure 3.

In EHDIs, the relative fixation of the proximal hepatic ducts to the liver can lead to a shearing force, inducing intraductal hypertension and tearing, as seen with high-speed deceleration [14, 17]. Another mechanism involves compression of the biliary system and gallbladder against the vertebral column and ductal blowout, which may be seen when the gallbladder rapidly empties into a short cystic duct $[2,8,16]$. Ischemic necrosis of the ducts has also been proposed, perhaps accounting for delayed injuries [18]. Extensive ductal dissection during surgery can also produce an ischemic injury. A combination of mechanisms is likely involved in each individual case.

Abdominal ultrasound (AUS) and computed tomography (CT) constitute the initial diagnostic workup. Ductal dilatation and/or periportal fluid collections raise the suspicion of bile duct injury [8]. Percutaneous evacuation of bile can help confirm the diagnosis [9]. In cases of persistent bile drainage, scintigraphy may be useful, although it is poor in pinpointing the site of injury $[6,19]$. Cholangiogram is the gold standard for defining a ductal injury [20]. More recently, ERCP has emerged as a valuable adjunct in treatment of EHDI, and can be both diagnostic and therapeutic $[12,21-23]$.
One third of EHDIs are missed at initial laparotomy or investigation, and another $2 \%$ are not recognized on repeat surgery $[8,12]$. Over $50 \%$ of patients with EHDIs who do not undergo immediate trauma laparotomy typically have a diagnostic delay of more than 1 day, which can result in significant morbidity and mortality $[2,8]$. Sterile bile causes minimal peritoneal reaction, with vague abdominal pain and distention, nausea, vomiting, and jaundice $[8,24]$. Liver injury is the most common associated injury (55\% of patients), followed by extremity (19\%), pelvic fractures (17\%), and splenic and gallbladder injury [12]. Pneumothorax, rib fractures, and head injury are less frequent. Others report combined injuries involving the duodenum, stomach, colon, pancreas, and non-EHDI biliary duct injuries $(5 \%)[12,25]$.

Mortality was reported in $3.8 \%$ to $12.7 \%$ cases of EHDI, with blunt injuries being associated with higher mortality than penetrating injuries $[1,2,12,25,26]$. EHDIs are associated with long hospitalizations (average of 40 days) and many potential complications [12]. Early complications include wound infection, abscess, and biliary fistula $[8,27,28]$. Late complications include ductal stricture with or without cholangitis and posttraumatic hepatic atrophy $[25,29,30]$.

When the diagnosis of EHDIs occurs during an emergent celiotomy, the primary focus should be on patient stabilization, hemostasis, temporizing stenting, ligation, and Ttube placement should be considered $[1,8,31]$. At the very least, the injured duct should be tagged and the area drained, with definitive repair performed later. Long-term stenting across injured hepatic ducts may be considered, even without suture repair [17, 32]. Choledochoenterostomy and hepaticoenterostomy have been used for major ductal injuries, including complete transections $[1,15,33]$. When performing biliary reconstruction, the size of the duct and viability of its blood supply have to be considered, and end-to-end ductal repair should be avoided in complete injury due to the risk of stricture formation $[8,16,25]$. Other techniques include repair with vein, serosal or jejunal patch $[33,34]$. Adequate operative drainage is essential [3]. Bilioenteric anastomoses produce good long-term outcomes in $85-90 \%$ of cases 
[35-38]. Long-term anastomotic stenting (6-9 months) has been supported by some authors $[25,36]$, while others stent for a shorter period of time or not at all $[35,39]$. Anastomotic stents decompress the biliary tree, allow postoperative radiographic followup, and there may be a correlation between outcome and the time stented as anastomotic catheters may limit the contraction of collagen and stricturing [25]. Opponents of stenting argue that stents contribute to complications (stent dislodgment, occlusion by biliary debris, and cholangitis) $[25,40]$. While many biliary strictures appear in the first 2 postoperative years, it may take up to 5 years for $80 \%$ of strictures to occur, with approximately $20 \%$ of failures after that period, suggesting that a long-term followup of 7-10 years may be optimal [25, 35, 41]. Tacking of the Roux-en-Y jejunal loop marked with metallic clips to the abdominal wall can help facilitate future biliary tree access [36].

\section{EMERGING ROLE OF ERCP IN MANAGEMENT OF EHDI}

Management of EHDIs depends on the patient's overall clinical status, associated injuries, and the location and extent of the injury [8]. Patients who are hemodynamically stable on initial presentation and do not require immediate surgical intervention can safely undergo nonoperative management of bile duct injuries - an attractive therapeutic alternative $[42,43]$. This is further supported by the use of ERCP in treatment of iatrogenic extrahepatic bile duct injuries, which is well described and accepted $[12,22]$.

More recently, ERCP has emerged as a valuable adjunct in treatment of EHDI, and has been used to define the anatomy of the injury as well as to provide definitive therapy [12, 2123, 43]. In fact, a total of 19 cases in this review involved ERCP utilization in either diagnostic or therapeutic capacity (Table 1). The safety and efficacy of ERCP has been advocated in increasing number of publications, with excellent $(>90 \%)$ ductal visualization success and low $(<10 \%)$ morbidity $[7,43]$.

Endoscopic retrograde cholangiopancreatography has been successfully utilized in treatment of hepatic ductal injuries both as a primary treatment modality and as an adjunct to surgery, with some of the patients having previously undergone at least one laparotomy [43]. Indeed, it may be that ERCP is the optimal choice for treatment of bile duct injuries regardless of whether the patient underwent recent surgery. One might speculate that performing a potentially therapeutic ERCP for EHDIs in the setting of a recent laparotomy may actually constitute the safest initial approach, given the possibility of postoperative adhesions and the risk of bile duct devascularization due to surgical dissection. In fact, at least one reported death was due to massive hepatic bleeding encountered during an operative attempt at repair of RHD stricture [25]. The usefulness of ERCP in such setting is exemplified by the current case, where the diagnosis of EHDI was not made until after the initial trauma laparotomy, and reoperation to restore biliary continuity would have been very difficult and risky. Not only did ERCP confirm the diagnosis of EHDIs and facilitated definitive treatment of the injury, but also indirectly pointed to the potential cause of surgical failure if operative management was attemptedsmall transected LHD that could not be traversed with the guidewire. Because surgical repair of small extrahepatic bile ducts can be exceedingly difficult $[62,63]$, a topic beyond the scope of this discussion, ERCP may be the preferred treatment method in this scenario as well.

In majority of reported cases, including the current report, ERCP-facilitated ductal stenting was performed $[8,10$, $16,43]$. In fact, ERCP with sphincterotomy and drainage avoids surgery in $70-90 \%$ of iatrogenic ductal injuries by reducing the biliary intraductal pressure gradient [42]. Percutaneous drainage of any bile collections should be performed as well, with prophylactic drainage suggested by some even in the absence of an active bile leak [43]. In the current case, while a CT scan revealed a fluid collection, it failed to fully delineate the anatomic injury. Much like in other reports of both traumatic and nontraumatic bile duct injuries, ERCP was used to define the anatomy of the injury and to treat it definitively with biliary decompression and stenting $[12,21-23]$. It is likely that endoscopic stenting provides similar effects to operative anastomotic stenting via biliary decompression and by potentially decreasing stricturing through limiting collagen contraction [25]. Failures of endoscopic therapy are rare, and have been associated with leaks from noncommunicating or anatomically "excluded" ductal injuries [42].

A recent review of EHDIs with an average followup period of 26 months reported an increasing use of ERCP in both diagnostic and therapeutic capacities [12]. Among patients treated primarily with ERCP, 9/19 had followup studies $[4,8,11,12,16,43,61]$. Among these patients, 8/9 showed resolution of biliary leak and no evidence of biliary stricture $[4,8,11,16,43,61]$ and $1 / 9$ showed nonvisualization of the previously injured LHD [11]. As more long-term followup data confirm good clinical results, the ERCP will likely take the dominant position as the initial treatment of choice for EHDIs.

Complication rates associated with ERCP use in the setting of bile duct injuries are low $(<10 \%)$ [7]. Reported postERCP complications include pancreatitis and persistent hyperamylasemia $[10,14]$. In addition, stent migration or clogging may occur [43]. In adult patients, stent migration has been noted in upto $5 \%$ of patients [10]. Stent clogging is more common, with upto $30 \%$ incidence within 3 months of stent placement [10]. There is also a low risk of infection and bleeding related to percutaneous catheter drainage of EHDIassociated bile collections [43]. Ductal stenosis at the site of injury is an important late complication of ERCP and stenting. It has been postulated that prolonged stenting (up to 12 months), sometimes with multiple stents, may provide both treatment and prevent further stricturing [42].

After a literature search was conducted, Table 1 was constructed to summarize all known cases of EHDIs from 1952 to 2006. Based on our case as well as the literature search, proposed diagnostic (Figure 4) and treatment (Figure 5) algorithms were designed in order to systematize clinical decision-making in the setting of EHDIs. These algorithms reflect the evolving role of ERCP in treatment EHDIs. 
TABLE 1: Collected summary of all reported cases of extrahepatic hepatic ductal injuries from 1925 to present.

\begin{tabular}{|c|c|c|c|c|c|c|}
\hline $\begin{array}{l}\text { Date, Author, (Ref.) } \\
\text { (chronological) }\end{array}$ & Age (y.) & Gender & $\begin{array}{l}\text { Mechanism of } \\
\text { injury }\end{array}$ & Nature of ductal injury & Treatment & ERCP \\
\hline 1925, Cope $[44]$ & 10 & $\mathrm{M}$ & MVC & Confluence of R \& LHD & Cholecystostomy drains & $\mathrm{N}$ \\
\hline 1929, Long [45] & 40 & M & $\begin{array}{l}\text { Crushed } \\
\text { between autos }\end{array}$ & Confluence of R \& LHD & Cholecystostomy drains & $\mathrm{N}$ \\
\hline 1938, Lewis [27] & 49 & $\mathrm{M}$ & MV versus PED & Confluence of R \& LHD & $\begin{array}{l}\text { Drainage. Followed by } \\
\text { re-drainage }\end{array}$ & $\mathrm{N}$ \\
\hline 1953, Walker [46] & 2 & M & $\begin{array}{l}\text { Run over by a } \\
\text { tractor }\end{array}$ & Confluence of R \& LHD & R-en-Y repair over stents & $\mathrm{N}$ \\
\hline 1955, Baty [47] & 25 & $\mathrm{M}$ & MVC & LHD laceration & Common duct T-tube & $\mathrm{N}$ \\
\hline 1955, Schaer [48] & 50 & M & Struck by a bull & $\begin{array}{l}\text { RHD lacerated anteriorly } \\
(0.5 \mathrm{~cm})\end{array}$ & CBD stent, drains & $\mathrm{N}$ \\
\hline 1956, Foman [49] & 34 & M & MVC & $\begin{array}{l}\text { R \& LHD near the } \\
\text { confluence }\end{array}$ & Cholecystostomy, drain & $\mathrm{N}$ \\
\hline 1961, Nikishin [50] & 3 & M & $\begin{array}{l}\text { Run over by an } \\
\text { auto }\end{array}$ & RHD laceration & Drains & $\mathrm{N}$ \\
\hline \multirow[t]{2}{*}{ 1964, Hartman [51] } & 2 & $\mathrm{~F}$ & MV versus PED & Confluence of R \& LHD & $\begin{array}{l}\text { Cholecystostomy with } \\
\text { drainage }\end{array}$ & $\mathrm{N}$ \\
\hline & 6 & M & MVC & $\begin{array}{l}\text { (1) Bile duct leak at } \\
\text { unknown site (2) LHD } \\
\text { transection }\end{array}$ & $\begin{array}{l}\text { Drains, primary repair over } \\
\text { catheters, common duct } \\
\text { tube, cholecystostomy, } \\
\text { feeding jejunostomy }\end{array}$ & $\mathrm{N}$ \\
\hline 1967, Noone [52] & 8 & M & $\begin{array}{l}\text { Bicyclist falling } \\
\text { onto handle bars }\end{array}$ & $\begin{array}{l}\text { (1) Lacerated R liver lobe } \\
\text { (2) R \& LHD disruption }\end{array}$ & $\begin{array}{l}\text { Primary anastomosis over } \\
\text { catheters, cholecystostomy, } \\
\text { drains }\end{array}$ & $\mathrm{N}$ \\
\hline 1967, Sewell [53] & 14 & $\mathrm{~F}$ & MVC & LHD avulsion & LHD ligation, $\mathrm{T}$ tube & $\mathrm{N}$ \\
\hline 1968, Maier [26] & 37 & $\mathrm{M}$ & MCC & RHD laceration (lateral) & Repair over T tube & $\mathrm{N}$ \\
\hline 1969, Haynes [54] & $\mathrm{N} / \mathrm{A}$ & $\mathrm{N} / \mathrm{A}$ & $\begin{array}{l}\text { Blunt abdominal } \\
\text { trauma }\end{array}$ & $\begin{array}{l}\text { (1) R hepatic lobe } \\
\text { laceration (2) LHD } \\
\text { laceration }\end{array}$ & $\begin{array}{l}\text { Drains, Primary ductal } \\
\text { repair }\end{array}$ & $\mathrm{N}$ \\
\hline 1969, Estrada [55] & 26 & $\mathrm{M}$ & MVC & LHD laceration, posterior & Repair over T-tube & $\mathrm{N}$ \\
\hline \multirow[t]{2}{*}{ 1972, Zollinger [32] } & 21 & $\mathrm{~F}$ & MVC & R \& LHD laceration & Repair over catheters, drain & $\mathrm{N}$ \\
\hline & 48 & M & MVC & LHD avulsion & $\begin{array}{l}\text { Drains, RHD anastomoses } \\
\text { to R-en-Y, stent, T-tube }\end{array}$ & $\mathrm{N}$ \\
\hline 1974, Williams [56] & 3 & $\mathrm{M}$ & MV versus PED & LHD avulsion & End-to end anastomosis & $\mathrm{N}$ \\
\hline 1980, McFadden [28] & 31 & $\mathrm{M}$ & MVC & Combined R \& LHD & Hepaticojejunostomy & $\mathrm{N}$ \\
\hline 1985, Jones [21] & 37 & $\mathrm{M}$ & MCC & Confluence of R \& LHD & R \& L hepaticojejunostomy & $\mathrm{N}$ \\
\hline 1985, Michelassi [2] & 9 & M & $\begin{array}{l}\text { Patient denied } \\
\text { any trauma }\end{array}$ & LHD partially severed & $\begin{array}{l}\text { Suture repair. Drains. } \\
\text { T-tube }\end{array}$ & $\mathrm{N}$ \\
\hline 1987, Salam [19] & 17 & $\mathrm{~F}$ & MVC & RHD laceration & Suture repair & $\mathrm{N}$ \\
\hline 1991, Dawson [3] & 17 & M & Crushed by a log & $\begin{array}{l}\text { LHD avulsion, } 3 \mathrm{~cm} \text { tear } \\
\text { across the junction of } \\
\text { CHD and RHD }\end{array}$ & $\begin{array}{l}\text { Suture repair of } \\
\text { RHD \& CHD, R-en-Y } \\
\text { hepaticojejunostomy }\end{array}$ & $\mathrm{N}$ \\
\hline 1991, Monk [34] & 14 & M & Bicycle crash & $\begin{array}{l}\text { LHD disruption } \\
\text { (noncircumferential) }\end{array}$ & $\begin{array}{l}\text { Vein patch cholangioplasty } \\
\text { with stent \& drainage }\end{array}$ & $\mathrm{N}$ \\
\hline 1992, Muin [24] & 45 & M & $\begin{array}{l}\text { Hit by falling } \\
\text { tree branch }\end{array}$ & $\begin{array}{l}\text { Confluence of R \& LHD } \\
\text { (superiorly) }\end{array}$ & $\begin{array}{l}\text { R-en-Y } \\
\text { hepaticojejunostomy }\end{array}$ & $\mathrm{N}$ \\
\hline \multirow[t]{3}{*}{ 1993, Hills [30] } & 18 & $\mathrm{~F}$ & MVC & LHD injury & Percutaneous stent & $\mathrm{N}$ \\
\hline & 15 & $\mathrm{~F}$ & MVC & LHD injury & $\begin{array}{l}\text { Cholecystectomy, omental } \\
\text { plug }\end{array}$ & $\mathrm{N}$ \\
\hline & 16 & $\mathrm{M}$ & MCC & LHD injury & Partial liver resection & $\mathrm{N}$ \\
\hline 1993, Moulton [10] & 5 & $\mathrm{~F}$ & MV versus PED & LHD tear & Stent placed via ERCP & $\mathrm{Y}$ \\
\hline 1994, Brenneman [57] & 36 & $\mathrm{M}$ & MCC & LHD injury & Repair over T-tube & $\mathrm{N}$ \\
\hline 1995, Gerndt [8] & 20 & $\mathrm{M}$ & MVC & L \& RHD injury & Primary repair. Drains. & $\mathrm{Y}$ \\
\hline
\end{tabular}


TABle 1: Continued.

\begin{tabular}{|c|c|c|c|c|c|c|}
\hline & 19 & M & MVC & LHD transection & $\begin{array}{l}\text { Drains, R-en-Y } \\
\text { hepaticojejunostomy }\end{array}$ & $\mathrm{N}$ \\
\hline & 21 & M & MVC & $\begin{array}{l}\text { (1) L \& RHD injury near } \\
\text { bifurcation (2) Transected } \\
\text { lateral LHD }\end{array}$ & $\begin{array}{l}\text { ERCP with stenting of } \mathrm{R} \\
\text { ductal system }\end{array}$ & $\mathrm{Y}$ \\
\hline 1995, Baer et al. [58] & 31 & M & Fell 10 meters & LHD injury & Drains & $\mathrm{N}$ \\
\hline 1995, Poli [9] & 12 & $\mathrm{~F}$ & $\begin{array}{l}\text { Kicked by a } \\
\text { horse }\end{array}$ & $\begin{array}{l}\text { Confluence of R \& LHD, } \\
\text { CHD tear }\end{array}$ & $\begin{array}{l}\text { Nasobiliary and } \\
\text { percutaneous drains }\end{array}$ & $\mathrm{Y}$ \\
\hline 1996, Eid [4] & 21 & M & $\begin{array}{l}\text { Crushed by a } \\
\text { container }\end{array}$ & ERCP, LHD tear & Stenting via ERCP & $\mathrm{Y}$ \\
\hline $\begin{array}{l}\text { 1996, Hayakawa et al. } \\
\text { [59] }\end{array}$ & 21 & M & MCC & LHD transection & Primary repair over stent & $\mathrm{N}$ \\
\hline 1996, Sharma [5] & 35 & M & $\begin{array}{l}\text { Fall from a } \\
\text { height }\end{array}$ & RHD bile leak & Endoscopic papillotomy & $\mathrm{Y}$ \\
\hline \multirow[t]{2}{*}{ 1997, Sakamoto [17] } & 23 & M & Fall from ladder & Confluence of R \& LHD & Drains at laparotomy & $\mathrm{N}$ \\
\hline & 22 & $\mathrm{M}$ & MV versus PED & LHD laceration & Stent at laparotomy & $\mathrm{N}$ \\
\hline 1999, Arkovitz [6] & 7 & M & MV versus $\mathrm{PED}$ & $\begin{array}{l}\text { (1) Complete avulsion of } \\
\text { LHD (2) Attenuated RHD }\end{array}$ & $\begin{array}{l}\text { Stenting, Drainage, } \mathrm{L} \text { and } \mathrm{R} \\
\text { hepaticojejunostomies }\end{array}$ & $\mathrm{Y}$ \\
\hline 1999, Simstein [60] & 21 & M & $\begin{array}{l}\text { Pinned under } \\
\text { automobile }\end{array}$ & $\begin{array}{l}\text { (1) Injury at R \& LHD } \\
\text { confluence (2) RHD } \\
\text { disruption }\end{array}$ & $\begin{array}{l}\text { Intraoperative placement of } \\
\text { drains }\end{array}$ & $\mathrm{Y}$ \\
\hline $\begin{array}{l}\text { 1999, Bin Yahib et al. } \\
{[14]}\end{array}$ & 3 & M & MV versus PED & Torn R \& LHD & $\begin{array}{l}\text { Primary repair of R \& LHD, } \\
\text { R-en-Y } \\
\text { hepaticojejunostomy }\end{array}$ & $\mathrm{Y}$ \\
\hline 2000, Sanders [7] & 11 & M & $\begin{array}{l}\text { All terrain } \\
\text { vehicle accident }\end{array}$ & LHD injury & $\begin{array}{l}\text { Cholecystostomy tube, } \\
\text { Jackson-Pratt }{ }^{\mathrm{TM}} \text { drains }\end{array}$ & $\mathrm{Y}$ \\
\hline \multirow[t]{2}{*}{ 2001, D’Amours [61] } & 34 & M & Fall 9 meters & R \& LHD injury & $\begin{array}{l}\text { ERCP. Sphincterotomy and } \\
\text { stenting }\end{array}$ & $\mathrm{Y}$ \\
\hline & 41 & M & MVC & LHD injury & $\begin{array}{l}\text { Drains, ERCP with } \\
\text { sphincterotomy and double } \\
\text { pigtail stent }\end{array}$ & $\mathrm{Y}$ \\
\hline 2001, Nuzzo [29] & 42 & $\mathrm{~F}$ & MVC & $\begin{array}{l}\text { (1) LHD transection (2) } \\
\text { LHD stricture }\end{array}$ & $\begin{array}{l}\text { LHD end-to-end } \\
\text { anastomosis. ERCP } \\
\text { stenting and serial dilations } \\
\text { of LHD stricture }\end{array}$ & $\mathrm{Y}$ \\
\hline \multirow[t]{2}{*}{$\begin{array}{l}2001, \\
\text { Rodriguez-Montes } \\
{[25]}\end{array}$} & N/A & $\mathrm{N} / \mathrm{A}$ & N/A & RHD laceration & $\begin{array}{l}\text { T-tube, RHD R-en-Y } \\
\text { choledochojejunostomy }\end{array}$ & $\mathrm{N}$ \\
\hline & N/A & M & $\mathrm{N} / \mathrm{A}$ & $\begin{array}{l}\text { (1) LHD transection (2) } \\
\text { RHD stricture (delayed } \\
\text { finding) }\end{array}$ & $\begin{array}{l}\text { Primary repair of LHD } \\
\text { transection. Endoscopic } \\
\text { stenting od RHD. }\end{array}$ & $\mathrm{Y}$ \\
\hline 2002, Sharpe [11] & 11 & M & $\begin{array}{l}\text { Sledding } \\
\text { accident }\end{array}$ & Transected LHD & $\begin{array}{l}\text { Percutaneous drainage of } \\
\text { subhepatic space and } \\
\text { transampullary stent }\end{array}$ & $\mathrm{Y}$ \\
\hline 2003, Nathan [16] & 17 & M & MVC & Confluence of R \& LHD & $\begin{array}{l}\text { Intraoperative placement of } \\
\text { drains. ERCP with stent } \\
\text { placement }\end{array}$ & $\mathrm{Y}$ \\
\hline \multirow[t]{2}{*}{ 2006, Almaramhi [43] } & 6 & $\mathrm{~F}$ & MVC & RHD & $\begin{array}{l}\text { ERCP with stent placement } \\
\text { and percutaneous drainage }\end{array}$ & $\mathrm{Y}$ \\
\hline & 6 & M & MVC & RHD & $\begin{array}{l}\text { ERCP with stent placement } \\
\text { and percutaneous drainage }\end{array}$ & $\mathrm{Y}$ \\
\hline Current case & 26 & M & MCC & $\begin{array}{l}\text { (1) Confluence of } \\
\text { R \& LHD (2) LHD injury }\end{array}$ & $\begin{array}{l}\text { External drainage, ERCP } \\
\text { with sphincterotomy and } \\
\text { CBD stenting }\end{array}$ & $\mathrm{Y}$ \\
\hline
\end{tabular}

Abbreviations: N/A = Data Not Available; ERCP = Endoscopic retrograde cholangiopancreatography; CHD = Common hepatic duct; LHD = Left hepatic Duct; RHD = Right hepatic duct; R \& LHD = Right and Left Hepatic Ducts; R = Right; L = Left; R-en-Y = Roux-en-Y; MVC = Motor vehicle crash; MV versus $\mathrm{PED}=$ Motor vehicle versus pedestrian. 


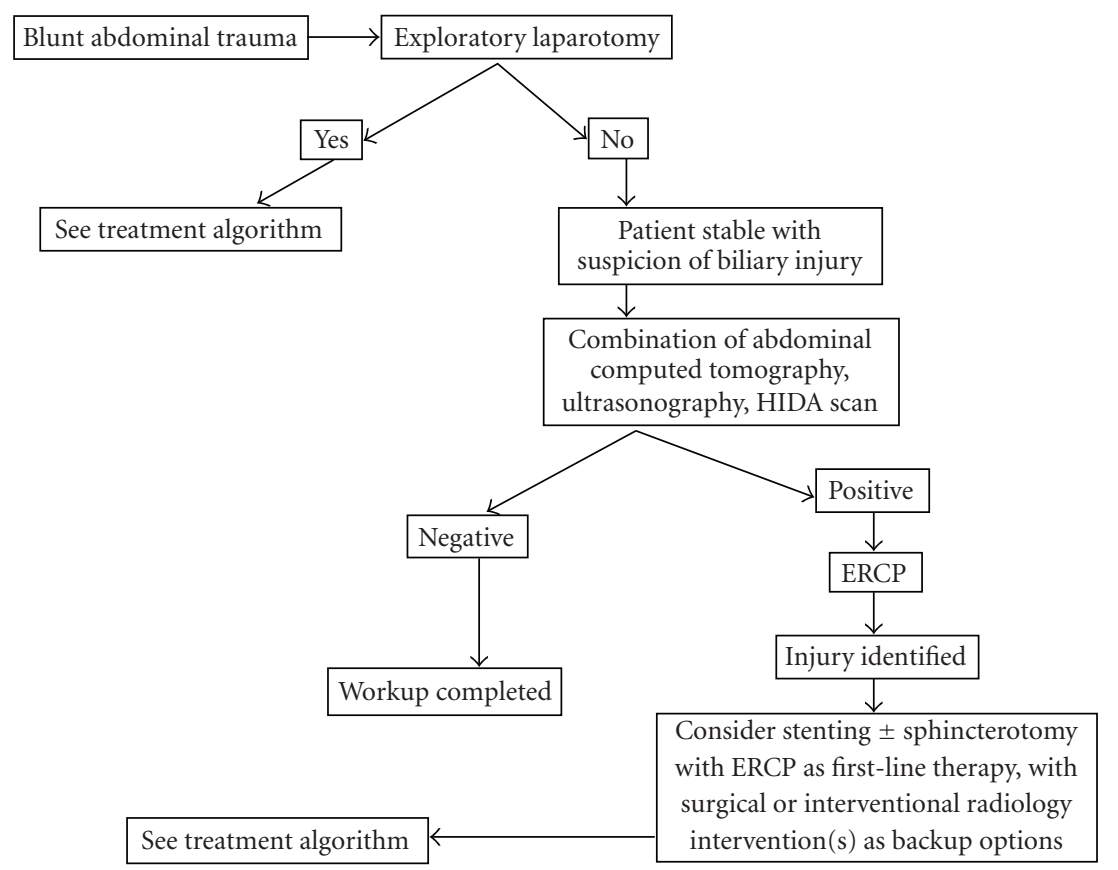

FIGURE 4: Proposed diagnostic algorithm for extrahepatic hepatic ductal injuries. ERCP = endoscopic retrograde cholangiopancreatography. $\mathrm{HIDA}=$ nuclear biliary scan.

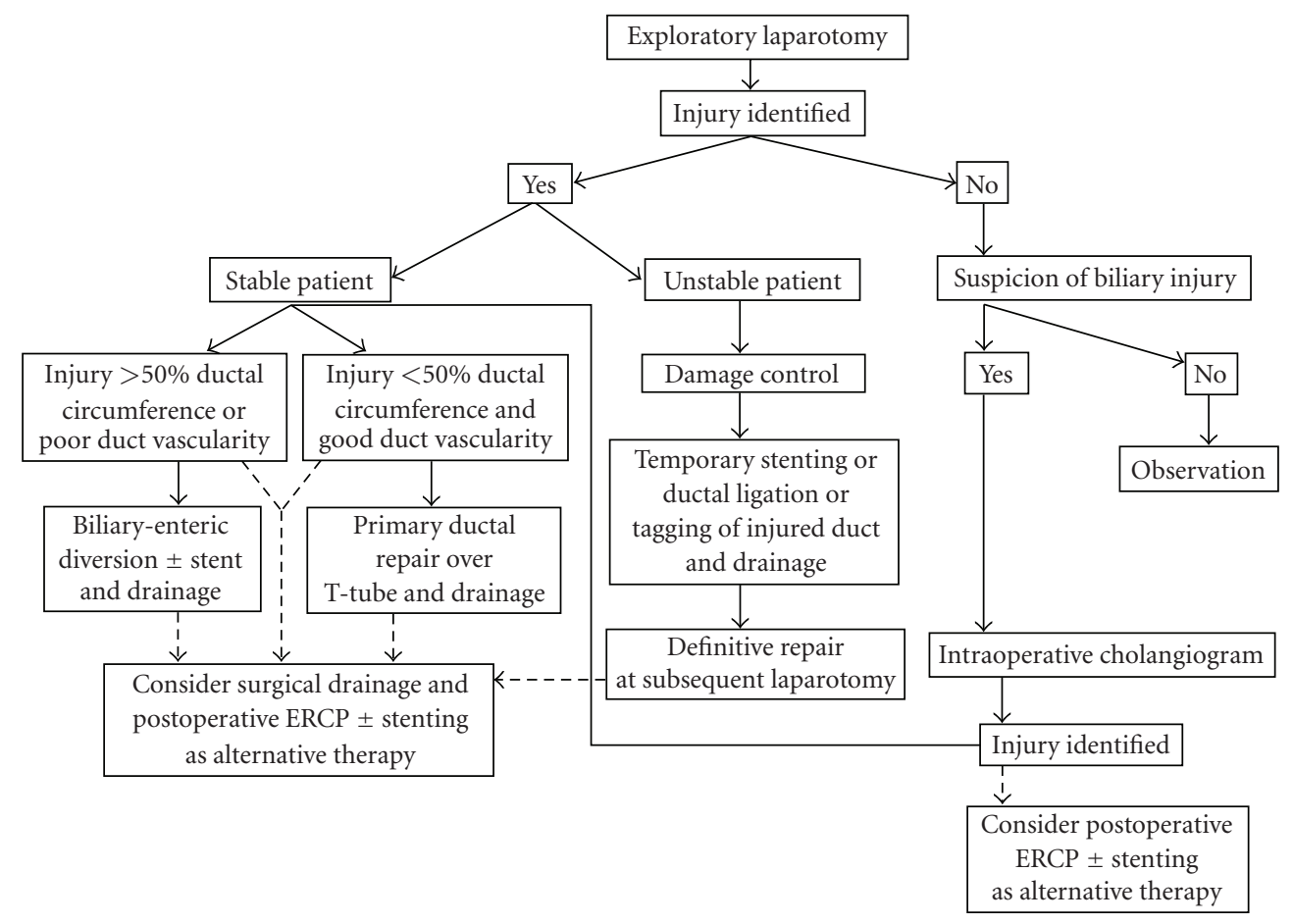

FIgURe 5: Proposed treatment algorithm for extrahepatic hepatic ductal injuries.

\section{CONCLUSIONS}

Because the clinical presentation is often insidious, EHDIs are frequently missed on the initial clinical evaluation. The management of EHDIs has changed over the last decade. Availability of ERCP presented trauma surgeons with a new diagnostic and therapeutic alternative. With good short-term results of ERCP being well established, a growing body of data is demonstrating equally good results on long-term followup. We recommend the use of diagnostic and treatment algorithms to standardize care, decrease diagnostic delay, and potentially improve outcomes. 


\section{REFERENCES}

[1] R. R. Ivatury, M. Rohman, M. Nallathambi, P. M. Rao, Y. Gunduz, and W. M. Stahl, "The morbidity of injuries of the extrahepatic biliary system," Journal of Trauma, vol. 25, no. 10, pp. 967-973, 1985.

[2] F. Michelassi and J. H. Ranson, "Bile duct disruption by blunt trauma," Journal of Trauma, vol. 25, no. 5, pp. 454-457, 1985.

[3] D. L. Dawson and G. J. Jurkovich, "Hepatic duct disruption from blunt abdominal trauma: case report and literature review," Journal of Trauma, vol. 31, no. 12, pp. 1698-1702, 1991.

[4] A. Eid, G. Almogy, A. J. Pikarsky, Y. Binenbaum, E. Shiloni, and A. Rivkind, "Conservative treatment of a traumatic tear of the left hepatic duct: case report," Journal of Trauma, vol. 41, no. 5, pp. 912-913, 1996.

[5] B. C. Sharma, A. Maini, and V. A. Saraswat, "Endoscopic management of perforation of right hepatic duct following nonsurgical abdominal trauma," HPB Surgery, vol. 10, no. 4, pp. 245-247, 1997.

[6] M. S. Arkovitz, H. Liang, H. L. Pachter, P. Alexander, R. M. Newman, and G. K. Gittes, "Complete biliary avulsion from blunt compression injury," Journal of Pediatric Surgery, vol. 34, no. 10, pp. 1559-1562, 1999.

[7] D. W. Sanders and D. A. Andrews, "Conservative management of hepatic duct injury after blunt trauma: a case report," Journal of Pediatric Surgery, vol. 35, no. 10, pp. 1503-1505, 2000.

[8] S. J. Gerndt, S. P. Seidel, P. A. Taheri, and J. L. Rodriguez, "Biliary tract injury following blunt abdominal trauma: case reports," Journal of Trauma, vol. 39, no. 3, pp. 612-615, 1995.

[9] M. L. Poli, F. Lefebvre, H. Ludot, M. A. Bouche-Pillon, S. Daoud, and G. Tiefin, "Nonoperative management of biliary tract fistulas after blunt abdominal trauma in a child," Journal of Pediatric Surgery, vol. 30, no. 12, pp. 1719-1721, 1995.

[10] S. L. Moulton, E. C. Downey, D. S. Anderson, and F. P. Lynch, "Blunt bile duct injuries in children," Journal of Pediatric Surgery, vol. 28, no. 6, pp. 795-797, 1993.

[11] R. P. Sharpe, M. L. Nance, and P. W. Stafford, "Nonoperative management of blunt extrahepatic biliary duct transection in the pediatric patient: case report and review of the literature," Journal of Pediatric Surgery, vol. 37, no. 11, pp. 1612-1616, 2002.

[12] N. P. Jaik, S. P. Stawicki, and B. A. Hoey, "Emerging role of ERCP in blunt extrahepatic hepatic duct injuries," Gastroenterology, vol. 130, no. 4, supplement 2, p. A863, 2006.

[13] T. Wainwright, “Letter," Medical Physics, pp. 362-364, 1799.

[14] S. Bin Yahib, A. Al Rabeeah, and A. Al Sammarrai, "An unusual bile duct injury in a child after blunt abdominal trauma," Journal of Pediatric Surgery, vol. 34, no. 7, pp. 1161-1163, 1999.

[15] M. D. Bourque, N. Spigland, A. L. Bensoussan, L. H. Garel, and H. Blanchard, "Isolated complete transection of the common bile duct due to blunt trauma in a child, and review of the literature," Journal of Pediatric Surgery, vol. 24, no. 10, pp. 1068-1070, 1989.

[16] M. Nathan, J. Gates, and S. J. Ferzoco, "Hepatic duct confluence injury in blunt abdominal trauma: case report and synopsis on management," Surgical Laparoscopy, Endoscopy \& Percutaneous Techniques, vol. 13, no. 5, pp. 350-352, 2003.

[17] Y. Sakamoto, N. Tanaka, T. Furuya, et al., "A simple stenting method for management of hepatic ductal injury secondary to blunt abdominal trauma: two case reports," Journal of Trauma, vol. 42, no. 6, pp. 1165-1168, 1997.

[18] J. F. Gately and E. J. Thomas, "Post-traumatic ischemic necrosis of the common bile duct," Canadian Journal of Surgery, vol. 28, no. 1, pp. 32-33, 1985.
[19] M. Salam, J. V. Glowniak, R. M. Vetto, J. E. Jarboe, J. E. Haines, and G. T. Krishnamurthy, "Detection of bile leakage from traumatic right hepatic duct laceration with technetium-99m DISIDA cholescintigraphy," Clinical Nuclear Medicine, vol. 12, no. 8, pp. 589-591, 1987.

[20] A. F. Roy, R. B. Passi, R. W. Lapointe, V. C. McAlister, M. H. Dagenais, and W. J. Wall, "Bile duct injury during laparoscopic cholecystectomy," Canadian Journal of Surgery, vol. 36, no. 6, pp. 509-516, 1993.

[21] K. B. Jones and E. Thomas, "Traumatic rupture of the hepatic duct demonstrated by endoscopic retrograde cholangiography," Journal of Trauma, vol. 25, no. 5, pp. 448-449, 1985.

[22] K. F. Binmoeller, R. M. Katon, and R. Shneidman, "Endoscopic management of postoperative biliary leaks: review of 77 cases and report of two cases with biloma formation," The American Journal of Gastroenterology, vol. 86, no. 2, pp. 227231, 1991.

[23] K. Sugimoto, Y. Asari, T. Sakaguchi, T. Owada, and K. Maekawa, "Endoscopic retrograde cholangiography in the nonsurgical management of blunt liver injury," Journal of Trauma, vol. 35, no. 2, pp. 192-199, 1993.

[24] A. Muin, Y. P. Leong, and S. K. S. Tay, "Laceration of the common hepatic duct bifurcation by blunt abdominal trauma," Injury, vol. 23, no. 6, pp. 422-423, 1992.

[25] J. A. Rodriguez-Montes, E. Rojo, and L. G.-S. Martín, “Complications following repair of extrahepatic bile duct injuries after blunt abdominal trauma," World Journal of Surgery, vol. 25, no. 10, pp. 1313-1316, 2001.

[26] W. P. Maier, W. P. Lightfoot, and G. P. Rosemond, "Extrahepatic biliary ductal injury in closed trauma," The American Journal of Surgery, vol. 116, no. 1, pp. 103-108, 1968.

[27] K. M. Lewis, "Traumatic rupture of the bile ducts," Annals of Surgery, vol. 108, no. 2, pp. 237-242, 1938.

[28] P. M. McFadden, G. Tanner, and A. Kitahama, "Traumatic hepatic duct injury: new approach to surgical management," The American Journal of Surgery, vol. 139, no. 2, pp. 268-271, 1980.

[29] G. Nuzzo, G. Clemente, F. Cadeddu, and M. Mutignani, "Complete trauma disruption of the left hepatic duct: endoscopic treatment after failure of surgical repair," Journal of Trauma, vol. 51, no. 1, pp. 159-161, 2001.

[30] M. W. Hills, A. J. Richardson, N. Tait, S. A. Deane, and J. M. Little, "Non-iatrogenic trauma to the extrahepatic biliary tract," Australian and New Zealand Journal of Surgery, vol. 63, no. 3, pp. 190-194, 1993.

[31] J. Cipolla, S. P. Stawicki, W. S. Hoff, et al., "A proposed algorithm for managing the open abdomen," The American Surgeon, vol. 71, no. 3, pp. 202-207, 2005.

[32] R. M. Zollinger Jr., R. T. Keller, and C. A. Hubay, "Traumatic rupture of the right and left hepatic ducts," Journal of Trauma, vol. 12, no. 7, pp. 563-569, 1972.

[33] P. G. Bade, S. R. Thomson, A. Hirshberg, and J. V. Robbs, "Surgical options in traumatic injury to the extrahepatic biliary tract," British Journal of Surgery, vol. 76, no. 3, pp. 256-258, 1989.

[34] J. S. Monk Jr., J. S. Church, and N. Agarwal, "Repair of a traumatic noncircumferential hepatic bile duct defect using a vein patch: case report," Journal of Trauma, vol. 31, no. 11, pp. 1555-1557, 1991.

[35] M. L. McDonald, M. B. Farnell, D. M. Nagorney, D. M. Ilstrup, and J. M. Kutch, "Benign biliary strictures: repair and outcome with a contemporary approach," Surgery, vol. 118, no. 4, pp. 582-591, 1995. 
[36] H. A. Pitt, T. Miyamoto, S. K. Parapatis, R. K. Tompkins, and W. P. Longmire Jr., "Factors influencing outcome in patients with postoperative biliary strictures," The American Journal of Surgery, vol. 144, no. 1, pp. 14-21, 1982.

[37] S. Misra, G. B. Melton, J. F. Geschwind, A. C. Venbrux, J. L. Cameron, and K. D. Lillemoe, "Percutaneous management of bile duct strictures and injuries associated with laparoscopic cholecystectomy: a decade of experience," Journal of the American College of Surgeons, vol. 198, no. 2, pp. 218-226, 2004.

[38] K. D. Lillemoe, G. B. Melton, J. L. Cameron, et al., "Postoperative bile duct strictures: management and outcome in the 1990s," Annals of Surgery, vol. 232, no. 3, pp. 430-441, 2000.

[39] W. H. Nealon and F. Urrutia, "Long-term follow-up after bilioenteric anastomosis for benign bile duct stricture," Annals of Surgery, vol. 223, no. 6, pp. 639-648, 1996.

[40] R. W. Parks and T. Diamond, "Non-surgical trauma to the extrahepatic biliary tract," British Journal of Surgery, vol. 82, no. 10, pp. 1303-1310, 1995.

[41] L. W. Way and J. E. Dunphy, "Biliary stricture," The American Journal of Surgery, vol. 124, no. 2, pp. 287-295, 1972.

[42] E. A. J. Rauws and D. J. Gouma, "Endoscopic and surgical management of bile duct injury after laparoscopic cholecystectomy," Best Practice \& Research: Clinical Gastroenterology, vol. 18, no. 5, pp. 829-846, 2004.

[43] H. Almaramhi and A. R. Al-Qahtani, "Traumatic pediatric bile duct injury: nonoperative intervention as an alternative to surgical intervention," Journal of Pediatric Surgery, vol. 41, no. 5, pp. 943-945, 2006.

[44] Z. Cope, "Extravasation of bile," British Journal of Surgery, vol. 13, no. 49, pp. 120-129, 1925.

[45] L. Long, "Traumatic rupture of the bile ducts," Southern Medical Journal, vol. 22, pp. 236-240, 1929.

[46] J. H. Walker, "Traumatic rupture of the bile-ducts," The Lancet, vol. 265, no. 6793, pp. 969-971, 1953.

[47] J. A. Baty, "Traumatic rupture of hepatic duct," British Journal of Surgery, vol. 43, no. 181, pp. 553-555, 1956.

[48] S. M. Schaer, J. M. Dziob, and R. K. Brown, "Bile duct rupture from external blunt trauma," The American Journal of Surgery, vol. 89, no. 2, pp. 745-747, 1955.

[49] J. J. Foman and J. R. Hindhaw, "Rupture of the hepatic ducts due to blunt trauma," Surgery, vol. 39, pp. 322-324, 1956.

[50] I. F. Nikishin, "Rupture of the extrahepatic ducts following a nonpenetrating injury to the abdomen," The Journal of the International College of Surgeons, vol. 36, pp. 573-580, 1961.

[51] S. W. Hartman and E. M. Greaney Jr., "Traumatic injuries to the biliary system in children," The American Journal of Surgery, vol. 108, pp. 150-156, 1964.

[52] R. B. Noone, J. A. Mackie, and R. Stoner, "Liver and bile duct laceration from blunt abdominal trauma in children," Annals of Surgery, vol. 166, no. 5, pp. 824-828, 1967.

[53] J. H. Sewell, "Avulsion of the left hepatic duct," Annals of Surgery, vol. 165, no. 4, pp. 628-631, 1967.

[54] C. D. Haynes, K. S. Given, H. H. Stone, and R. B. Smith III, "Nonsurgical trauma to the extrahepatic bile ducts," Southern Medical Journal, vol. 62, no. 11, pp. 1323-1326, 1969.

[55] R. L. Estrada and N. G. Sutherland, "Subparietal or nonpenetrating traumatic rupture of the biliary tree," British Journal of Surgery, vol. 56, no. 2, pp. 85-91, 1969.

[56] G. R. Williams, "Experiences with surgical reconstruction of hepatic duct," Annals of Surgery, vol. 179, no. 5, pp. 540-548, 1974.
[57] F. D. Brenneman, S. B. Rizoli, B. R. Boulanger, and S. S. Hanna, "Blunt left hepatic duct injury," Injury, vol. 25, no. 7, pp. 465467, 1994.

[58] H. U. Baer, A. Czerniak, J.-J. Moser, and W. Schweizer, "Segmental bile duct injury after blunt abdominal trauma: a difficult diagnosis," Hepatogastroenterology, vol. 42, no. 2, pp. 103105, 1995.

[59] M. Hayakawa, A. Horiguchi, S. Ishihara, K. Miura, S. Miyakawa, and K. Mizuno, "Complete transection of the left hepatic duct due to blunt abdominal trauma," Hepatogastroenterology, vol. 43, no. 11, pp. 1395-1398, 1996.

[60] N. L. Simstein, "Isolated blunt trauma injury to the hepatic duct," International Surgery, vol. 85, no. 1, pp. 55-56, 2000.

[61] S. K. D’Amours, R. K. Simons, C. H. Scudamore, A. G. Nagy, and D. R. G. Brown, "Major intrahepatic bile duct injuries detected after laparotomy: selective nonoperative management," Journal of Trauma, vol. 50, no. 3, pp. 480-484, 2001.

[62] P. Compagnon, M. Lakehal, and K. Boudjema, "Roux-en-Y limb anastomosed to small biliary duct," Annales de Chirurgie, vol. 128, no. 3, pp. 191-194, 2003.

[63] K. Hasegawa, M. Makuuchi, K. Kubota, T. Takayama, and M. Watanabe, "Reconstruction of small and fragile bile ducts without mucosa-to-mucosa anastomosis," Archives of Surgery, vol. 135, no. 5, pp. 596-599, 2000. 


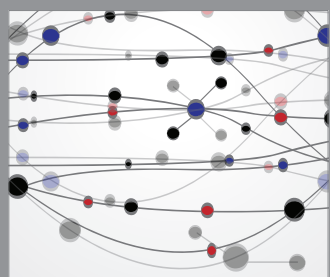

The Scientific World Journal
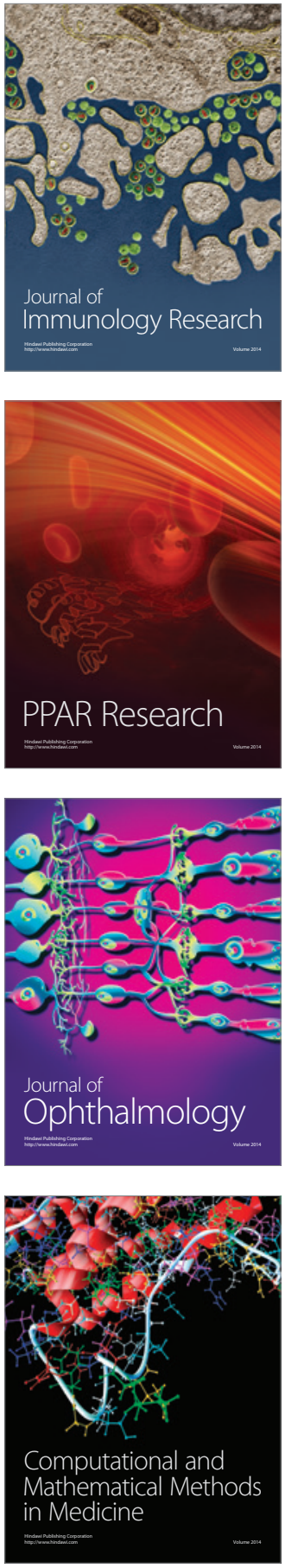

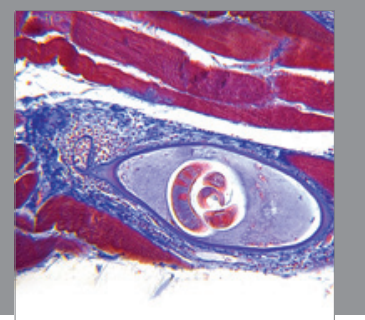

Gastroenterology

Research and Practice
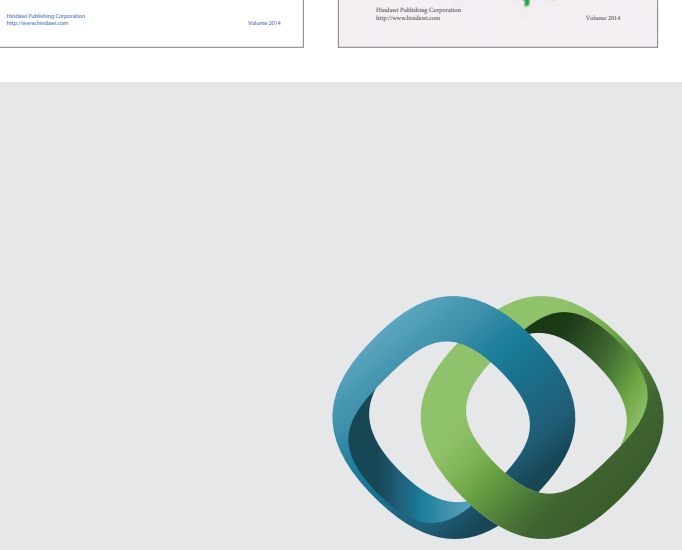

\section{Hindawi}

Submit your manuscripts at

http://www.hindawi.com
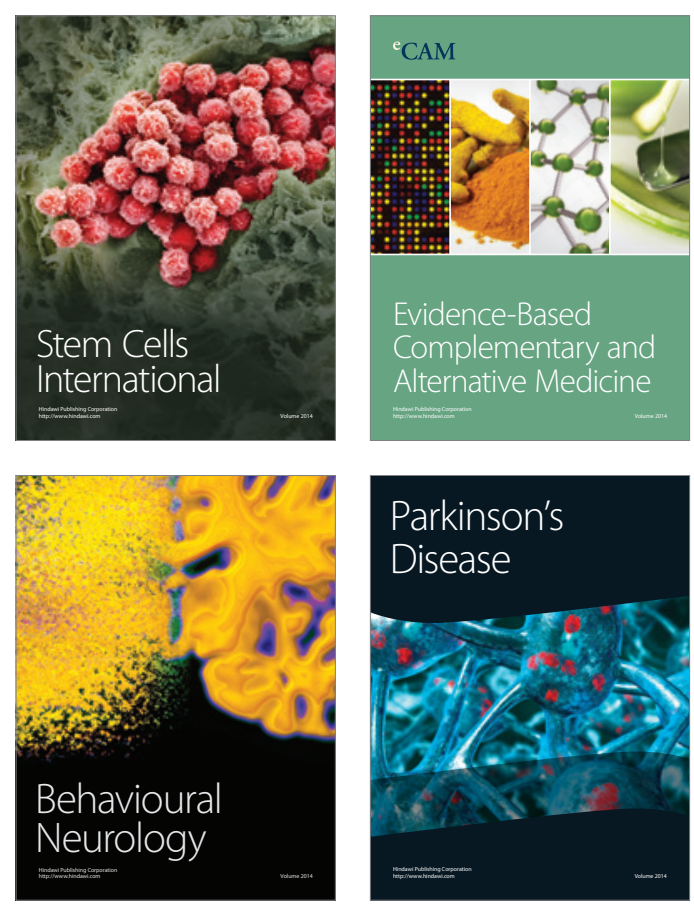

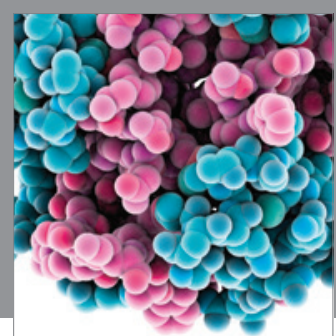

Journal of
Diabetes Research

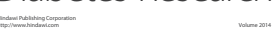

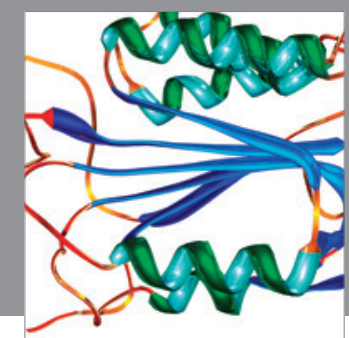

Disease Markers
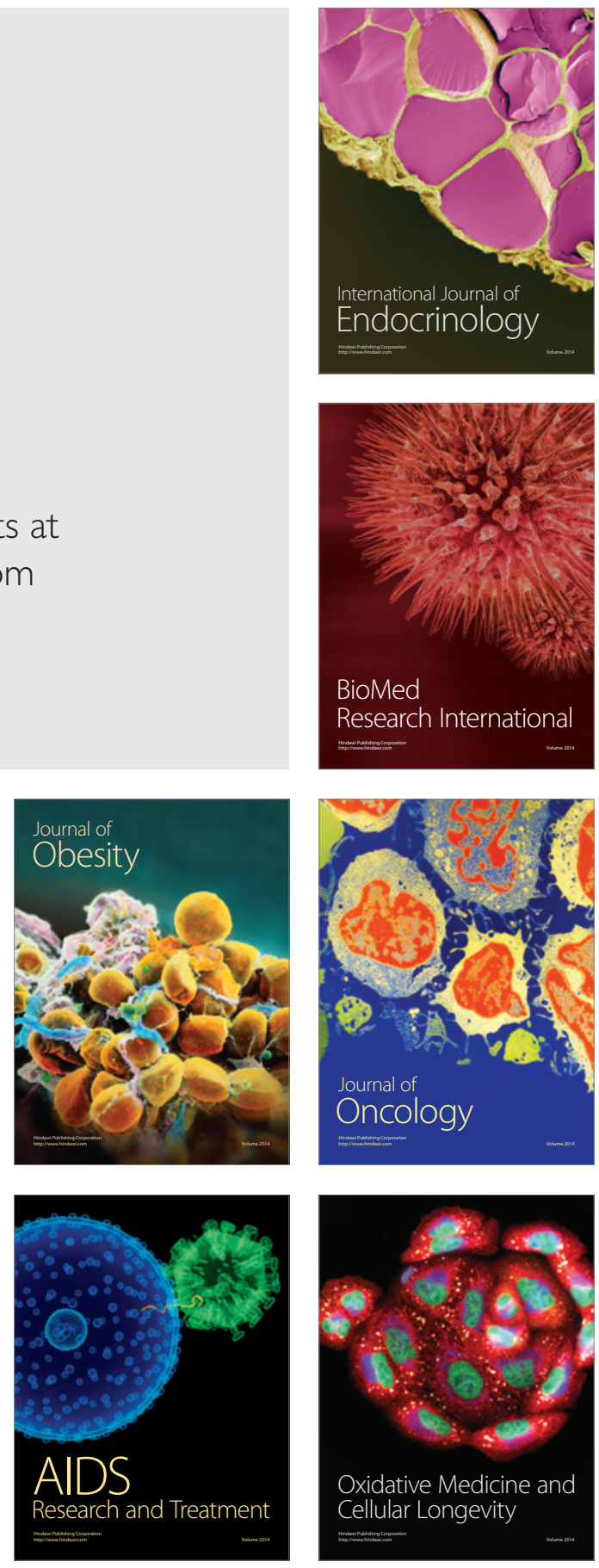